\title{
Better Health than Health Care: moving up, down, and out
}

\author{
Emanuel de Kadt
}

Underlying the different definitions of the 'PHC approach' are a number of widely accepted principles. Some of the more important ones can be distilled from the Declaration of Alma Ata [WHO/UNICEF 1978]. There is the demand that health care services should be organised so that all who are in need have broadly equal chances of access, the demand for equity. Then there is the principle of linking health provision to other aspects of socioeconomic development, which leads to the call for intersectoral collaboration. There is also the view that PHC cannot merely be handled from 'up high'. This translates into two further principles. The first is that the health system itself needs to be decentralised. Secondly, PHC calls for the greatest possible measure of individual and family selfreliance, and community participation. This paper will examine intersectoral collaboration, decentralisation and community participation as conditions for moving in the direction of an equity-based PHC system.

\section{Historical Roots of Present Distortions}

In practice, what goes under the name of the PHC approach remains largely anchored to issues of health care and concerns itself only contingently with questions of health. That is the result of the accumulated weight of over a century of concentration on health service development. The debates of the early years strongly suggest that this concentration was not historically inevitable [Turshen 1977], and modern discussions of that period leave little doubt that it was - in retrospect - undesirable. The arguments of McKeown [1979] regarding the historical causes of health improvements in the now industrialised countries have come to be quite widely accepted. Alastair Gray deals with them in some detail in his article in this Bulletin. McKeown argues that since the nineteenth century specifically medical inventions and interventions had less impact on health than improvements in the environment and in living conditions, through the effects of nutrition, sanitation and a falling population growth rate. That 'demedicalised' view of health has by now entered into the discussions of health policy: hence the PHC principle that health may be more influenced by broad development policies than by what is done through Ministries of Health, and the emphasis in WHO's strategy of 'Health For All by the Year 2000' (HFA/2000) on the 'intersectoral' aspects of health policy [WHO 1979]. All this is just a translation into terms relevant to policy makers in the health sector of the theoretical insights of McKeown and others.

Nineteenth century public policy dealt with a more restricted range of issues than public policy today, also in the field of health. Politicians or civil servants had never heard the term intersectoral collaboration, regarded as so central to the implementation of the PHC approach today. Yet in a country such as the UK, health policy - when it eventually emerged straddled a number of sectors. In the face of fierce working class protest, struggles and even riots directed against exploitation and harsh living and working conditions, pressures built up from members of parliament, civil servants, and health inspectors for something to be done about the appalling state of health of the poor in the newly industrialised towns. From the 1840 s legislation began to be passed encompassing sanitation, water supply, housing and working conditions [Davies 1955]. This broad approach to health gradually weakened. The earlier interest in the social and economic conditions that determine health declined, as the threat to public health receded with the successes of sanitary engineering. Simultaneously, as scientific medicine showed its impressive capacity for diagnosis and cure of individual conditions, it demanded and received increasing attention from policy makers and civil servants. More time was needed to cope with the expanding hospitals and their demands, and to deal with the pressure on resources that resulted from medical developments. Similarly, within medicine itself, primary care came to be relegated to an inferior position: real medicine was practised in the hospitals. And the techniques of hospital medicine, which increasingly expressed an 'engineering' approach to health [Powles 1973] — the injunction was to deal with the 'part' that had gone wrong - found their way back into primary care. Health care, after first losing sight

Bulletin, 1983, vol 14 no 4, Institute of Development Studies. Sussex 
of people's environment and socioeconomic conditions, increasingly also lost sight of the individual 'as a whole'.

This kind of evolving health care system was transplanted to developing countries, often by colonial administrations. It helped to control disease in the towns, and especially among the colonial civil servants, military personnel, and settlers, and/or the local economic and political elites, who were able to benefit from the new scientific medicine. Those privileged groups saw to it that the advances of medical science and technology in the industrialised countries were followed closely overseas and adopted wherever possible. In most developing countries the proportion of the population to whose advantage the system operated grew only very slowly. That contrasted starkly with the situation in the industrial countries of the North. As these became richer and the economic and political power of the industrial working class increased, living standards improved, welfare systems were set up, and political representation, on the whole, was widened. Yet nothing like that was occurring in the colonies where the new hospitals were being erected. Nor did the achievement of independence make much difference in most places: usually there were no social or political mechanisms to counteract the push towards inequality which, in those circumstances, accompanied the constant upgrading of health care for the favoured few. The prevailing health policies, then, matched social structures and vested interests. In response to that situation, equity is now strongly emphasised by the PHC approach. It aims to reverse the negative impact on poor countries of earlier health policies.

One of the other central principles of PHC, community participation, can also be understood from such a historical perspective. Modern scientific medicine, as it evolved in the industrial countries of the North, developed a powerful medical ideology to give a very special role to the health professionals. Health care (or rather medical care) became the prerogative of the expert. It was 'delivered' to passive patients, who were expected to be active at most in following the expert's specific instructions [de Kadt 1982a]. In less developed countries, where patients were poorly educated, people could not relate to modern medicine with scientific awe, though they often did assimilate it to more familiar experiences of a traditional, perhaps even 'magical', kind [Scarpa 1981]. So involvement with the emerging modern health care system in promoting health, even understanding of the issues, were minimal. The effects of this situation were only made worse by the general absence of participatory mechanisms in the political sphere. There was no way in which ordinary people could have a say in the decisions that affected their every-day lives - and in many developing countries that continues to be true today.

The PHC approach proclaims to the world that it is necessary to check the forces that have led to this situation. Its success depends more on grappling with those forces of class and profession, less on the abstract acceptance of the PHC doctrine. Even so, the fact that the governments of all the world's nations have formally underwritten the doctrine is not without significance. At the very least it may provide ammunition, to those seeking social and political change, of a kind to which the powers-that-be cannot easily take exception.

\section{Community Participation}

The term community participation is used rather loosely, especially in 'international discourse'. ${ }^{1}$ Often, participation refers merely to 'contributions' of community members to health service activities - be it in kind, cash, or labour, or even in terms of their enlistment as village health workers. For present purposes this conception of participation will be left aside; here I shall deal exclusively with participation in the sense of decision-making, and more specifically with the notion of pushing its locus 'down' towards the people most directly concerned.

Decision-making has both a private and a public dimension. In their private lives people are constantly faced with the need to make decisions, even though in fact they often leave decision-making to others. In the previous section I briefly discussed the view that professionals have gradually become more dominant in matters of health, 'lay' people more passive. 'Participation' can be a way to help people overcome that passivity. It may enable them to have a greater degree of autonomy, more say, in the personal and community health actions that concern them. It can help to alter the balance between professional 'expertise' and lay 'experience'. In the countries of Western Europe and North America that has been vigorously promoted by the women's movement, at first in relation to over-medicalised conceptions of childbirth especially, later more generally through the idea of self-help groups, a concept that has spread widely [Katz and Bender 1976]. The upsurge of interest in so-called alternative medicine has similar overtones. Such groups/movements have a strong element of involving people together in a 'community' - of community participation. Though still very much a minority phenomenon, its importance seems to be growing.

In less developed countries people also get involved with each other in matters of health, but there the physicians' 'medicalised' view of health and illness

'A number of discussions have systematically analysed the different meanings given to the concept. See: White [1981]; de Kadt [1982b]. 
never achieved the monopoly it established in the industrialised countries. Throughout Asia, Africa, and Latin America traditional health care systems, some more, some less formalised, continue to be widely supported. They are used not only by the many for whom access to the modern system is difficult or impossible, but also by urban (and often welleducated) people who move freely between modern and traditional practitioners [Twumasi 1975]. Usually these systems are built around private transactions between patient and practitioner, but in some societies there are strong communal - even cult - elements interwoven with such practices [de Souza Queiroz 1982].

However, the public/political dimension of decisionmaking is more important than the private one to a discussion of the theory and practice of PHC today. This extends the idea of increased involvement and responsibility from the personal sphere to the way people can influence the institutions and structures that operate in the health sector. Such influence remains very weak in most places. Rarely do hospitals or health centres take account of the views of the people they are expected to serve. (Village health workers cannot really fulfil this function, as they are mostly transmitters of messages from the health care system to the community rather than vice versa.) Attempts to institute participation tend to be experienced as challenges to the authority of the health workers who are in charge. ${ }^{2}$ Relations between 'patients' and health sector staff, as well as internal institutional hierarchies, reflect the 'expert' dominance discussed above, and are also an expression of the class structure and its manifestations throughout the society.

There are significant differences in this respect between different types of society, and the sociopolitical context sets limits to what can be expected from participatory mechanisms [de Kadt 1982b]. In most less developed countries the democratic political institutions which can mitigate class dominance are weak or nonexistent, and the state is firmly under the control of those who also dominate the economy (even in many countries where the economy is largely 'socialised'). Participation makes demands upon those in control. The dominant structures, economic or political, will have to adjust if such demands are to be accommodated. Therefore, participation is at best an evolving process, whose tensions and contradictions are created and resolved through stages of demands and accommodation [Bhaduri and Rahman 1982].

Class struggles in the countryside after revolutionary upheavals, where the new central government supports the peasantry (and vice versa), usually lead to

This is particularly true in Latin America [de Kadt 1982b], even - as Werner [1983] makes clear — in Cuba. a forced accommodation by those previously in control. Popular participation is therefore given a strong boost, and it is from post-revolutionary (socialist) societies that we get the most promising, even glowing, accounts of participation [Segall and Williams 1983]. Yet, many such accounts are based on limited official or officially-inspired information, the only kind allowed to be published, and they often lack the critical judgments with which less egalitarian, nonsocialist societies tend to be approached. Their biggest problem is perhaps that they shed little light on the new control mechanisms put in place of the old ones, through the ruling party or the strong arm of the state, which can strip participation of much of its effects. ${ }^{3}$

In most poor countries, then, in the health sector as elsewhere, mechanisms for participation - in the sense of providing for social control or for a measure of 'co-determination' - are either absent or less effective than they are made out to be. In truth, governments and bureaucracies do not really want participation, which is time-consuming and uncomfortable, and not always conducive to 'efficiency' [Maeda 1982]. Overall, the capacity of 'health committees' to have an effective influence on the health services, upwards from the community level, must remain in doubt.

There seems, however, to be more scope for community involvement in decision-making in smallscale projects, sponsored by non-government organisations. Voluntary agencies tend to have a flexibility which makes experimentation with such mechanisms relatively easy. Moreover, their ethos frequently expresses a strong concern with equity, and persons who become involved in leadership roles in such projects often emphasise the importance of listening to the people with whom they work. It is not surprising, therefore, that we hear of thriving health committees and other forms of community involvement. These experiences are interesting, though it is not always easy to separate the charismatic role of the project leader from the participatory inputs of the community members [Newell 1975].

So it would be wrong to write health committees off altogether - there are situations in which they have proved their worth. Yet in general there is less merit in setting up a separate participatory structure in the health sector than in using wider non-sectoral mechanisms (village or district development committees, for example), especially if these exist already. Health committees are liable to take over the approach to health that is prevalent in the health sector. In most places this continues to be 'over-

\footnotetext{
3 The belated 'discovery', now that the subject is no longer taboo in China itself, of the shadow-side of the Cultural Revolution is a case in point. In the health field a notable exception to this one-sidedness is David Werner's excellent account of the Cuban health care system [Werner 1983].
} 
medicalised', and as a result it is likely that little attention will be given to the intersectoral aspects of health (see below).

And what can be said about participation higher up, at the district ${ }^{4}$ level, for example? Is that likely to give the people a better chance to make their voice heard, directly or through their representatives? This question takes us straight to the issue of decentralisation. For the views of local people cannot be taken into account at the district level, if those administratively responsible for health and health care are themselves wholly bound by decisions and regulations that come from above.

\section{Decentralisation and Community Participation}

Decentralisation is a complex process that may be promoted in terms of 'efficiency' as much as of 'politics'. If intermediate levels have no other role than the implementation of decisions made higher up, they may lack the necessary flexibility for adjustment to local conditions, and their staff may feel little commitment to the work in which they are engaged. As a result, the bureaucracy will not function efficiently. By giving greater discretionary powers to lower level administrators, this problem may be overcome. Nevertheless, in those circumstances the central government or ruling party may still keep strict political control over regional or local governments and administrations. It can reserve many decisions to itself. Partly this is necessary to safeguard nationally agreed policies, such as PHC and its equity orientation, for example through budgetary mechanisms designed to ensure that these policies are reflected in resource allocation at the lower levels (UNICEF/ WHO 1981]. More generally, the central power can keep close control over the appointment of lower level officials or the selection of local candidates for election. Administrative decentralisation does not necessarily go hand in hand with devolution of political power to (elected) local governments, so that these can, within specified limits, take genuinely independent decisions [Apthorpe and Conyers 1982].

Nor does it, in the case of the health sector, necessarily have any effect on the autonomy or influence of the people whom the health workers are expected to serve. How those people are supposed to be involved when regions, provinces and districts make their own (health) plans, and do more to run their own affairs, is not often explained by the relevant administrative ordinances. If it is examined [Maeda 1982], it may transpire that the inputs are largely symbolic, because illiterate peasants cannot easily relate to the processes of government planning and resource allocation. The

" 'District' is used here to indicate the lowest, formally organised, level of local government and decentralised administration, also for the health services. officials do not have the time for explanations, and the district councillors are also over-awed by technical jargon and bureaucratic mumbo-jumbo.

That is why it is of interest to approach participation not only as a problem at the community level, but also as an issue of the devolution of power 'down' from the centre. The district is so worthy of attention because it is there that the formal administrative and political authority are exercised which directly affect the lives of the people at the grass roots, in the communities. Communities usually do not themselves make formal inputs into policy-making or control: if mechanisms for that exist, they only come into play at the district level or higher up. These mechanisms are not only a matter of greater or lesser decentralisation of the Ministry of Health (MoH). They also differ with the extent to which the wider political system has been decentralised, with how much devolution of political authority there has been to the lower levels. The responsibility for certain government functions may have been handed over to elected provincial or district authorities. The organisation of PHC, for example, may be entrusted to district councils, even if the funds continue to be mainly provided by central government and norms are set by the $\mathrm{MoH}$ in the national capital. In that case, those who exercise political control over the health care services for the community are the local councillors. Much then depends on whether they see health and health care in terms of the PHC approach, or whether they are interested mainly in the improvement of facilities in the district towns.

The mere existence of formal representative mechanisms does not ensure that the interests of the rural poor are adequately taken into account. In many places class divisions and inequalities in ownership and income are the dominant feature of the countryside. Local leaders who become local councillors, and then speak for the community, are often better-off people whose interests are quite different from those of the really poor [Bhaduri and Rahman 1982]. When community members experience local councillors as distant, unhelpful or even corrupt, they usually have good reasons for it. Moreover, though councillors always have some first hand experience of the functioning of local services, the picture with which they are formally presented is painted (and filtered) by the very persons who are themselves in charge: the schools' inspector or the district medical officer of health, for example. Hence the importance of mechanisms, 'from above', which try to ensure compliance with national policy, for example through control of resource allocation - at least where central government is concerned about equity. Equally or more important, 'from below', are grass roots community participation mechanisms: they can create channels through which ordinary people make their views known to those who are involved in decision- 
making in a more formal sense, and put pressure on them. Such mechanisms may, therefore, help counteract the tendency, widely documented in all sectors, for services to benefit mainly the well-to-do [Lamb and Schaffer 1981]. They may also fulfil that extremely important function of helping the mass of the people to achieve their rights, to activate and implement laws that can so easily remain dead letters.

Whether those mechanisms will be successful in this depends on the wider sociopolitical situation (few immediate results can be expected in a repressive police state!), and also on the 'sponsorship' of the participation mechanisms [de Kadt 1982b]. On the whole, community participation does not arise spontaneously, but has to be stimulated initially by agents external to the community. Such sponsors usually say that they want to make communities more self-reliant, more capable of influencing their own fate, better able to contribute to decision-making. But if those sponsors are themselves from government agencies or in other ways closely linked to the dominant sociopolitical institutions, will they want to see communities challenge the status quo? 'Participation' can become largely a matter of compliance with the views that come from above, be it from central government or from the district administration [Werner 1980]. This is so in socialist societies as much as in capitalist ones. Nevertheless, the fact that the state is predominantly conservative, manipulative and mistrustful of uncontrolled participation does not mean that state agencies can never play a constructive role at the grass roots. One should beware of regarding the state as altogether monolithic, and all its agencies as pursuing indentical ends by identical means: 'space' can exist for divergent views and programmes, particularly within the social sectors [Dore and Mars 1981].

\section{Health as Development: intersectoral issues}

Health policy is paying increasing attention to intersectoral issues, and the health sector to what happens 'out there'. Most of the extant discussion, however, has concerned itself with the national level.

WHO has been actively promoting the idea of national health development networks (NHDNs). Such networks process information from a variety of sources, within the health sector and outside it. One of their more important roles is to formulate and lay out the policy alternatives that exist, so that policymakers can assess the different options over the entire span of health-related policies, plans and programmes. They link government units and other organisations. The $\mathrm{MoH}$ plays a key role, especially its planning section; others involved may be health-related ministries, the national planning office, university departments and research institutions. Early assessments, based on material provided by the networks themselves, are encouraging [WHO 1983].

There is less experience with political institutions meant to give expression to the intersectoral approach. There has been some discussion of these under the rubric of national health councils (NHCs), which appear to function well in a number of countries. NHCs are conceived as political fora which consider the health implications of national development plans and also approve special health-related intersectoral plans or programmes. In addition, they provide the basic legitimation for intersectoral collaboration [WHO 1981]. Without such legitimation, few bureaucracies would be prepared to embark upon the innovations involved in intersectoral initiatives. Even with it, it is hard for them to put aside the usual rivalries, jockeying for power, or political differences, and to overcome the widespread duplication of functions and activities, and their incompatible perspectives.

Yet, the most import ant practical questions arise away from the national centre, in regions, provinces and again especially in districts. The district is not only the seat of the local authority to which power over such areas as PHC may have been devolved. It is also the place closest to the grass roots where line ministries may still have offices, the final link in a chain of command that goes all the way back to the centre. However modest the buildings which house the agricultural extension officer, the district community development officer, or the area water authority manager, there they sit, and implement the programmes and projects that are part of their ministry's broader plans and express its ethos. All of them, as well as the district medical officer of health, may deal with problems of water supply, or of food production and hence nutrition. Each of them, however, may have a different and incompatible approach to the issues, and their sectoral rules and regulations may make cooperation very hard indeed.

The very language they use may make mutual communication and understanding difficult. They may not define the subjects of their activities in the same way, may 'label' them quite differently [Wood 1983]. They may see their 'target group' variously: as small farmers (not the landless or the women); as women qua potential participants in sewing clubs (not women as carriers of water or tillers of subsistence plots); as those 'at risk' from disease (not those 'at risk' of poverty from the effects of the structure of ownership and production). ${ }^{5}$ More generally, their 'professional culture' may dispose them to wholly different styles of interaction. Most of them will have internalised that professional culture during their training. It may never have been discussed explicitly, 
let alone compared to the approach of other professional groups, or subjected to a critical analysis. Physicians and nurses, for example, are likely to be imbued with the conventional 'medicalised' view of health, have no more than a limited understanding of the PHC approach, and regard technical expertise as providing the justification for using authority vis-à-vis their staff and their 'patients'. Agricultural extension officers may think largely about the technical issues of growing crops efficiently and the consequent income generation; what may elude them are such matters as the possible effects on health - perhaps via a change in the resources at the disposal of women - of shifting the balance of production from subsistence to cash crops. Community development workers may have an egalitarian and 'participative' approach to their work: they may have little time for 'technocrats' who come and tell people what to do and how to do it, but also little understanding of the importance of productivity, efficiency, or accumulation.

For persons with such diverse backgrounds to work together is quite a challenge. It is rather like setting up an interdisciplinary research project: the effort is great and the outcome uncertain. People will soon discover that cherished views are not necessarily shared by others and that perspectives on the same reality can differ; for all, the process will be time-consuming. More senior officials, usually busier and more set in their ways, may find it especially hard to make the effort - though arguably they are more secure than those lower down, and should be more willing to take risks. At the district level, too, there will be problems, especially if officials are harrassed and overworked. Nevertheless, the case can be made (though at present on the basis of rather limited evidence) that intersectoral collaboration is more easily achieved at that level, as the scale there is smaller, the number of people involved fewer, and personal contact less formal.

There is an alternative way of dealing with intersectoral issues: let one person 'encompass' all sectors. Straddling sectoral differences in approach can come easily to unusual individuals, on their own in charge of projects. There are many examples of 'unconventional doctors', who have led projects with a broad interpretation of health that have branched out into non-medical activities [Newell 1975; Rifkin 1980]. Yet the experience with such projects, as with integrated rural development projects (whose lessons are quite relevant to this discussion [Honadle et al 1980]), suggests that they have three kinds of limitation. First, they are not easily replicable. Second, they do not fit into the established patterns of

\footnotetext{
5 Malnutrition is often labelled as a problem of mothers not feeding their children 'properly', so that women are blamed for the end result of a process whose origins lie outside the household altogether [Wheeler 1983]
}

public administration, and by that very fact they provide no guide to solving the problems of government intersectoral collaboration. Third, they are often dependent on separate outside funding, maybe from abroad, making them even less compatible with established government procedures, and also financially vulnerable.

If such multisectoral projects are not the multipurpose answer, then it is necessary to continue with attempts at intersectoral bridge-building. Much in this connection remains poorly understood, and there is a need for careful monitoring, analysis and discussion of such procedures as are being tried. If governments are serious about intersectoral collaboration, then they have to make it attractive and rewarding to the people who staff the different sectors, both in institutional and in personal terms. If it is the $\mathrm{MoH}$ which is promoting the idea, it will have to convince other ministries that the effort is worthwhile. Usually, $\mathrm{MoHs}$ are not among the departments with the greatest political influence, so it may be preferable for the initiative to come from somewhere else in the government, for example from the Prime Minister's Office, or the Ministry of Planning and Development. The national level must either take the lead, or at least create the legal and political space for regional or district levels to experiment; lower level bureaucrats are especially cautious animals and know that they break established rules and procedures at their peril. Yet ultimately interdepartmental committees in the capital may be less useful than working parties in the province or district; a regional health development network may have a greater impact than its national equivalent. Alternatives need to be tried and evaluated; all too little is known about these issues.

\section{Concluding Remarks}

This article has left many questions unanswered, and also reviewed a rather large number of problems obstacles - to making community participation, decentralisation and intersectoral collaboration work. That is, work in general, but more specifically work on behalf of PHC and its principle of equity. This was inevitable, given the nature of the evidence. Yet there is also positive experience, and it should be possible to learn from this and build on it. Not by mindless copying, since the web of interconnections with wider social, economic and political structures is too dense, and simple transplants do not work. Certain strategies, however, should pay off. They would involve carefully planned readjustments of existing institutions and procedures, and a willingness to engage in considerable experimentation. They would also take account of the fact that within the health sector institutions, in addition to the issues of structure, it is often people who are 'the problem' 
- because people have established ways of doing things, people have personal ambitions and rivalries, people represent vested interests, and people can very effectively throw a spanner into the most elaborately constructed reorganisation wheel. This means that nothing can be taken for granted and that attempted changes need to be carefully monitored and evaluated.

There remains the broader based socioeconomic opposition to PHC, which emanates from the class structure and the people who enjoy its established privileges. If those who would benefit from change can organise and mobilise, and make their voices heard, it may be possible to face such opposition head on. More often, such flexing of muscles leads to compromises - perhaps not a reduction in resources for urban hospitals, but at least a freeze on them. No-one can ever know where the limits of the possible lie. There may be indications: some leaps may clearly not be feasible. Yet in the final analysis the possible can only be determined by challenging the boundaries of the existing - in health as much as in any other area of human endeavour.

\section{References}

Apthorpe, R. and D. Conyers, 1982, 'Decentralisation, recentralisation and popular participation in developing countries: towards a framework for analysis, Development and Peace, vol 3, autumn, pp 47-59

Bhaduri, A. and M. A. Rahman (eds), 1982, Studies in Rural Participation, Oxford and IBH Publishing Co, New Delhi, Bombay and Calcutta

Davies, I. G., 1955, Modern Public Health for Medical Students, Arnold, London

Dore, R. and Z. Mars (eds), 1981, Community Development, Croom Helm and UNESCO, London

Honadle, G. et al, 1980, IntegratedRural Development: making it work?, Development Alternatives Inc, Washington DC

de Kadt, E., 1982a, 'Ideology, social policy, health and health services: a field of complex interactions', Social Science and Medicine, vol 16 no 6, pp 741-52

-1982b, 'Community participation for health: the case of Latin America', World Development, vol 10 no 7, pp 573-84; (a shortened version appeared in Morley et al (eds), 1983)

de Souza Queiroz, M., 1982, The Social Construction of Health and Illness in the Region of Uguape, Brazil, $\mathrm{PhD}$ dissertation, University of Manchester

Katz, A. H. and E. J. Bender (eds), 1976, The Strength in Us: self-help groups in the modern w'orld, Free Press, New York

Lamb, G. B. and B. B. Schaffer, 1981, Can Equity be Organised?, Gower Press, Farnborough
McKeown, T., 1979, The Role of Medicine: dream, mirage or nemesis?, Basil Blackwell, Oxford

Maeda, J. H. J., 1982, 'Peasant organisation and participation in Tanzania' in A. Bhaduri and M. A. Rahman (eds)

Morley, D., J. Rohde and G. Williams (eds), 1983, Practising Health for All. OUP, Oxford, New York and Toronto

Newell, K. W. (ed), 1975, Health by the People, WHO, Geneva

Powles, J., 1973, 'On the limitations of modern medicine', Science, Medicine and Man, vol 1 no 1, pp 1-30

Rifkin, S. B. (ed), 1980, 'Health: the human factor', Contact, Special Series no 3, World Council of Churches, Christian Medical Commission, Geneva, June

Scarpa, A., 1981, 'Pre-scientific medicines: their extent and value', Social Science and Medicine, vol 15A no 3, part 2, May

Segall, M. and G. Williams, 1983, 'Primary health care in Democratic Yemen: evolution of policy and political commitment' in D. Morley et al (eds)

Turshen, M., 1977, 'The political ecology of disease', Review of Radical Political Economics, vol 9 no 1, pp 45-60, spring

Twumasi, P. A., 1975, Medical Systems in Ghana, Ghana Publishing Corporation, Accra-Tema

UNICEF/WHO, 1981, joint committee on health policy, National Decision-making and Primary Health Care, WHO, Geneva

Werner, D., 1980, 'Health care and human dignity' in S. B. Rifkin (ed)

-1983, 'Health care in Cuba: a model service or a means of social control - or both? in D. Morley et al (eds)

Wheeler, E. F., 1983, 'To feed or to educate: targeted nutrition interventions', Nutrition Policy Unit, London School of Hygiene and Tropical Medicine, London, mimeo

White, A., 1981, 'Community participation in water and sanitation: concepts, strategies and methods', Technical Paper no 17, International Reference Centre for Community Water Supply and Sanitation, Rijswijk, June

WHO, 1979, Formulating Strategies for Health for All by the Year 2000, WHO, Geneva

-1981, 'National health councils', document SHS/81.1, WHO, Geneva

-1983, 'Report of interregional consultation on national development networks (NHDNs) Colombo, Sri Lanka, 15-19 November 1982', document SHS/83.2, WHO, Geneva

-UNICEF, 1978, Primary Health Care, report of the international conference on primary health care, Alma Ata, USSR, 6-12 September, WHO, Geneva

Wood, G. D., 1983, 'Claimants or participants? The case of the Intensive Rural Works Programme, Bangladesh', University of Bath, September, mimeo 